\title{
Espaço e território: as bifurcações da ciência regional
}

Space and territory: the bifucartion of regional science

Espace et territoire : les bifurcations de la science regionale

\section{Paul Claval}

\section{OpenEdition}

\section{Journals}

\section{Edição electrónica}

URL: http://journals.openedition.org/espacoeconomia/94

DOI: $10.4000 /$ espacoeconomia.94

ISSN: 2317-7837

\section{Editora}

Núcleo de Pesquisa Espaço \& Economia

\section{Refêrencia eletrónica}

Paul Claval, «Espaço e território: as bifurcações da ciência regional ", Espaço e Economia [Online],

1 | 2012, posto online no dia 19 janeiro 2013, consultado o 19 abril 2019. URL : http://

journals.openedition.org/espacoeconomia/94 ; DOI : 10.4000/espacoeconomia.94

Este documento foi criado de forma automática no dia 19 Abril 2019.

(C) NUPEE 


\section{Espaço e território: as bifurcações da ciência regional}

Space and territory: the bifucartion of regional science

Espace et territoire : les bifurcations de la science regionale

\section{Paul Claval}

\section{EDITOR'S NOTE}

Esse artigo é uma versão sintética em relação ao original "Espace et territoire: les bifurcations de la science régionale”, publicado em Géographie, Économie et Société, vol. 10, pp. 157-184, 2008/2. A presente versão foi editada e traduzida no âmbito do Laboratório de Política, Epistemologia e História da Geografia (LAPEHGE/UFRRJ), com apoio da FAPERJ, pelo professor Guilherme Ribeiro (UFRRJ).

\section{Introdução}

1 Falar de ciência regional é analisar temáticas desenvolvidas por disciplinas que se ignoraram até meados dos anos 50, mas que dialogaram em seguida sem perder suas especificidades. Na primeira metade do século passado, a idéia de região resultava do cruzamento de três abordagens essencialmente econômicas: a economia espacial, a teoria das relações econômicas internacionais e a geografia econômica.

2 A primeira bifurcação é anunciada no decorrer dos anos 30 mas só se realizará nos anos 50. Ela alia à economia espacial e à teoria das trocas internacionais os resultados da macroeconomia. Os geógrafos - que, durante muito tempo, trabalharam sobre o tema regional - se uniram ao movimento. A urgência levou planejadores e urbanistas a participarem da reflexão. Naquela altura, sociólogos e politólogos ainda não estão representados. 
3 No decorrer dos anos 70, as orientações definidas em meados do século XX serão questionadas. A ruptura com a macroeconomia é profunda: acentua-se o local, o territorial e a relação com o global.

\section{A origem das reflexões sobre espaço e região}

\section{0 papel pioneiro dos saberes geográficos}

4 A curiosidade pela distribuição desigual dos fatos humanos e econômicos se desenvolveu a partir do século XVII: a riqueza se espalha ao longo dos rios, dos cursos d'água navegáveis e perto das cidades (DOCKÈS, 1969). Estas observaçõs pertencem a um novo gênero: a ciência cameralista dos autores alemães - ou, no sentido inicial do termo, a estatística. Ainda não se trata da economia. Por sua vez, a geografia tem então outras preocupações : estabelecer o mapa exato do mundo (GODLEWSKA, 1999).

5 Até meados do século XIX, a curiosidade pelo espaço sugere às ciências sociais em gestação muitas questões às quais elas procuram responder.

\section{Um primeiro grupo de reflexões econômicas sobre o espaço}

6 Do terreno mal diferenciado dos primeiros saberes geográficos, três famílias de saberes relativos ao espaço que não apresentam nenhum ponto em comum surgirão na primeira metade do século XIX: a economia espacial, a teoria das relações internacionais e a geografia econômica (em sua primeira versão).

7 A teoria econômica apreende o espaço como um obstáculo aos transportes e como um fator de produção. Os efeitos da distância explicam a localização das produções agrícolas (von THÜNEN, 1826), das produções industriais (LAUNHARDT, 1882 ; WEBER, 1909) e dos serviços (CHRISTALLER, 1933 ; LÖSCH, 1938). Dotações naturais e Estados são levados em consideração, mas não estão no cerne da problemática.

8 Igualmente, a teoria das trocas internacionais analisa o espaço de duas maneiras (RICARDO, 1817): enquanto fator de produção e enquanto conjunto dos territórios nacionais desigualmente dotados; os países são separados por fronteiras que deixam passar os bens, mas não os fatores da produção. A conclusão é simples: cada país tira vantagem da especialização permitida pela troca dos produtos. Sob esse formato, eles exportam uma parte dos fatores de que dispõem abundantemente e importam aqueles que lhe faltam. O momento onde a baixa dos lucros intervém é, assim, retardado. Na teoria das trocas internacionais, não há lugar para os possíveis efeitos do progresso.

Dos anos 1850 aos anos de 1920, a maioria dos economistas ignora o espaço: quando eles notam os efeitos que a ele estão ligados, atribuem ao mesmo nomes que não permitem reconhecer sua origem - caso das economias externas, p.ex. (MARSHALL, 1890). A economia espacial só se desenvolve na Alemanha e nos países escandinavos (PONSARD, 1958).

10 A geografia econômica vem de Carl Ritter. Este se interessava pela circulação, que assegura tanto a difusão das espécies vegetais cultivadas e animais domésticos em espaços cada vez mais largos quanto a difusão de determinados gêneros aos países que não são capazes de produzi-los. O desenvolvimento da navegação a vapor acelera essas transformações (RITTER, 1833/1974, p. 132-150). A geografia econômica (RITTER, 
1836/1974, p. 151-165) acentua as propriedades nativas dos lugares em matéria de produção e as que a difusão das espécies domésticas deu origem, bem como o papel dos transportes. Ela descreve as áreas de produção e as correntes de trocas que tais áreas alimentam - e que se articulam ao redor dos mercados. Essa geografia econômica ignora os Estados - salvo para precisar a contribuição de cada país aos diversos ramos da produção.

11 Numa obra em dois volumes, Karl Andrée esboça o modelo dessa geografia econômica (ANDRÉE 1861, 1874). Sistematizado por Götz (1892), seu trabalho, é imitado na Inglaterra (CHISHOLM, 1889) e na França (DUBOIS et KERGORMARD, 1897). Suas bases permanecem intocadas até os anos 1930. Uma única inovação, porém de vulto: a emergência da idéia de desenvolvimento sustentável (Friedrich, 1904).

12 A idéia das vantagens comparativas [dotations em facteurs] é comum às diversas reflexões sobre espaço e economia desenvolvidas a partir dos anos de 1810 e 1820 . No restante, elas são diferentes: a economia espacial concebe o espaço como um obstáculo, a teoria das relações internacionais como um mosaico e a geografia econômica como um labirinto de circuitos.

\section{Urbanistas e planejadores}

13 O planejamento do território e a organização dos espaços urbanos sempre acompanharam as geoestratégicas políticas e econômicas. A partir do século XVIII, os novos meios de transporte trazem as vantagens de uma vida de relações a espaços que até então as ignoravam. Planejar é desenhar vias, organizar redes. Essa aventura se repete por três vezes: a partir de 1750 , para estradas e canais; a partir de 1840 , para ferrovias. E, com os canais transoceânicos, ela assume dimensão internacional.

Os problemas colocados pelos espaços urbanos são diferentes. O planejamento de espaços já construídos passa por novas passagens, pela composição de redes adutoras de água e esgoto e pela criação de espaços verdes - conforme a Paris de Haussmann. Na periferia, a abertura de novas áreas para urbanização repousa sobre a construção de estradas, vias férreas e linhas de tramway.

15 A acumulação da pobreza e de problemas sociais nas zonas rapidamente modificadas pela industrialização leva a conceber a cidade como um organismo que sofre deficiências patológicas. Estas dizem respeito às vias públicas, à habitação, à higiene. Para garantir uma intervenção eficaz, é mister repará-las.

16 Patrick Geddes (1915) e os urbanistas da Escola Francesa (BERDOULAY et CLAVAL, 2001) sublinham as interconexões locais, ‘territoriais'. Lewis Mumford é bastante sensível a isso e, no início dos anos 1920, tenta fundar o planejamento à luz da teoria regional (MUMFORD, 1922).

\section{Outros saberes sobre o espaço: a geografia regional}

17 Entre o início do século XIX e os anos de 1930, desenvolvem-se outros saberes sobre o espaço; porém, eles não tem a dimensão econômica ou impactos diretos sobre o planejamento.

o que a geografia humana descobre é a existência de fatos estruturais no domínio espacial: os espaços são diferenciados por grupos que não exploram o ambiente da mesma 
maneira em todos os lugares e não praticam o mesmo gênero de vida. Isso conduz a uma certa organização regional do espaço, evidenciada pelos geólogos desde o fim do século XVIII (GALLOIS, 1908). Ao lado da região natural e sua face humana, a região "geográfica", existem regiões agrícolas e regiões industriais, regiões caracterizadas por suas formas de sociabilidade e regiões desenvolvidas ao redor das cidades (CLAVAL, 1998; GALLOIS, 1908 ; Vidal de la BLACHE, 1888 ; 1903 ; 1904). Estas assumem um papel cada vez maior após a construção das redes férreas (Vidal de la BLACHE, 1910).

\section{Outros saberes sobre o espaço: a morfologia social}

19 Na medida em que se fixa sobretudo aos fenômenos de classe, a sociologia não cria uma perspectiva original sobre o espaço. As distribuições que ela estuda são apenas reflexos da divisão do trabalho.

20 A idéia segundo a qual o contraste entre cidades e campos constitui um problema social maior está presente no pensamento social alemão, pelo menos, desde Marx. Ferdinand Tönnies a teoriza associando a idéia de Gemeinschaft (comunidade) ao mundo camponês e a idéia de Gesellschaft (sociedade) aos espaços urbanos (TÖNNIES, 1944/1887). As reflexões de Georg Simmel e Max Weber estão baseadas na grande cidade.

21 Émile Durkheim parte das noções de Tönnies para criar a morfologia social (JONES, 1993). Para ele, a oposição das formas de sociabilidade entre cidade e campo resulta da desigual densidade populacional; precisa ele, da sua desigual densidade moral (DURKHEIM, 1893). Durante muito tempo a morfologia social é ilustrada apenas por alguns artigos (MAUSS et BEULAT, 1904/1905).

Paralelamente, a Escola da Ecologia Urbana de Chicago sublinha a complexidade da arquitetura social das cidades (BURGESS, 1925). As comunidades que as compõem competem por espaço e se perseguem mutuamente.

23 A seu turno, Maurice Halbwachs articula morfologia social e ecologia urbana (HALBWACHS, 1938): ele explora a idéia de densidade moral atendo-se à maneira como as representações sociais pesam sobre as distribuições e como a memória está associada aos lugares (HALBWACHS, 1925; 1941).

\section{A quase ausência das ciências políticas}

No concerto das curiosidades relativas ao espaço que aparecem na segunda metade do século XIX, as Ciências Políticas estão praticamente ausentes. A idéia passada pelo espaço como estruturas que modelam, retardam ou aceleram as evoluções políticas não amadurece muito antes dos anos 1910 (FAVRE, 1989). É só então que André Siegfried toma consciência do profundo enraizamento das convicções de direita da França do Oeste (SIEGFRIED, 1913).

Por sua vez, Max Weber propõe uma análise sociológica do poder que considera a diversidade de suas formas e de seus impactos sobre o espaço (WEBER, 1971, 2004). Em oposição ao poder puro, à autoridade legítima e às diversas formas de influência, ele lança as bases de uma diferenciada geografia das formas políticas. Um pouco nesse sentido são as reflexões sobre a dominação que Gramsci traz de seus anos de cativeiro. 


\section{Uma primeira bifurcação : o surgimento da ciência regional}

\section{O desenvolvimento desigual e as taxas de crescimento}

O nascimento da indústria moderna conferiu à Europa, Estados Unidos e posteriormente ao Japão um considerável dinamismo. Os países temperados que o povoamento branco estava em vias de conquistar também se beneficiaram.

A I Guerra Mundial desestabiliza a Europa, no que certas regiões industriais começam a entrar em declínio. A Grande Crise confere uma dimensão trágica a esses problemas. Os Estados não podem permanecer indiferentes a ela (GOTTMANN et al., 1952). Suas intervenções se revelam eficazes, tal como mostra a ação da Tennessee Valley Authority nos Estados Unidos e a criação dos primeiros parques industriais nas antigas bacias hulhíferas da Grã-Bretanha.

O planejamento regional moderno nasce do desigual dinamismo territorial, cuja Grande Crise faz tomar consciência. Os problemas sociais de certas regiões são tão preocupantes que os governos renunciam ao liberalismo puro. Entretanto, eles ainda não dispõem de teorias que justifiquem suas intervenções.

Olhemos para a URSS: para eles, a planificação centralizada dá ao regime soviético os meios de a tudo controlar. Ilusão: o marxismo não diz nada sobre a organização do espaço. Será necessário esperar até os anos 40 para que que reflexão sobre os "complexos regionais de forças produtivas" progridam (SAUSHKIN, 1962). De qualquer maneira, eles teriam um papel minoritário na tomada de decisões.

Os estudos conduzidos durante a II Guerra permitem descobrir a gravidade do desenvolvimento desigual; a reconstrução implica ações de vulto. Ao planejamento territorial nas escalas regional e nacional soma-se o planejamento resultante das necessidades das cidades. Seu crescimento é estimulado pelo impulso demográfico e pelos excedentes de mão-de-obra rural criados pela mecanização do campo. 0 uso do automóvel torna possível o escalonamento, mas provoca o congestionamento dos centros.

31 É nesse contexto que nasce a ciência regional: ela atrai pesquisadores vindos das mais diferentes disciplinas. Eles trazem conhecimentos em plena renovação.

\section{As novas bases da economia e da região}

32 A economia dispõe de uma tripla vantagem sobre as outras ciências sociais: (i) seus conhecimentos têm valor prescritivo; (ii) a teoria espacial e a teoria da especialização internacional já explicam boa parte da distribuição da produção; (iii) a macroeconomia reaprende a pensar a economia como feita de conjuntos submetidos a mecanismos globais (KEYNES, 1936).

O interesse pela teoria da especialização territorial renasce no entre-guerras (HECKSCHER, 1949/1919; OHLIN, 1932). Ao seu fim, a pesquisa avança um pouco mais (SAMUELSON, 1948, 1949). Seus resultados parecem confortar as teses liberais: a equalização do preço dos fatores de produção, promessa da máxima eficácia global, resulta automaticamente das trocas - se nada vier atrapalhá-las. 
34 A teoria espacial afirma-se graças aos trabalhos que Walter Christaller (1933) e August Lösch (1938) consagram aos lugares centrais e graças à formulação teórica que este último confere ao conjunto (LÖSCH, 1940). Igualmente, as pesquisas de Hotelling (1929) também possuem papel importante. Apontamentos sintéticos facilitam o aceso a esse aspecto do pensamento econômico (PONSARD, 1955, 1958; ISARD, 1956).

Walter Isard mobiliza os resultados da macroeconomia para esclarecer as economias regionais (ISARD, 1951, 1956). Os efeitos multiplicadores do investimento ou do comércio exterior são evidenciados. Tais resultados se aplicam a todas as escalas - cidade, região, Estado (Boudeville, 1961, 1962, 1963, 1966, 1968).

Alguns temas revelam-se particularmente fecundos, tais como economias externas (MARSHALL, 1890), economias de escala (YOUNG, 1928) e custos de transação (COASE, 1937). As duas primeiras chamam cada vez mais atenção (SCITOVSKY, 1954). Elas também dizem respeito às famílias, que vêem aumentar ou diminuir a utilidade dos lugares onde residem em função das atividades distribuídas nas proximidades do entorno (DAVIES e WHINSTON, 1962, 1964).

Três ramos alimentam a reflexão econômica sobre a região, mas sem que isso ainda resulte numa teoria unificada. Todavia, progressos importantes são realizados nesse domínio. O velho modelo de von Thünen é transposto aos espaços urbanos, onde a demanda por terrenos ocorre ao mesmo tempo da parte das empresas, que maximizam seus lucros, e de particulares, que a utilizam dessa mesma forma (ALONSO, 1964). A partir daí, dispõe-se de uma teoria do espaço urbano e de uma teoria das redes urbanas. Porém, a despeito de certos avanços (BERRY, 1964; BERRY e HORTON, 1969), elas não são unificadas. Geógrafos (VANCE, 1964) e economistas (LEVEN, 1977) sublinham a emergência da cidade policêntrica.

38 No plano internacional, destacam-se ou o papel negativo dos efeitos de demonstração, a fragilidade da poupança e os círculos viciosos que ela produz e a perda constituída por um fundo-trabalho [épargne-travail] que permanece inutilizado, ou as condições necessárias a serem reunidas de modo a conseguir a decolagem e o acesso à fase de crescimento sustentado característica dos países industrializados modernos. As interpretações sobre o desenvolvimento desigual promovem uma síntese dessas orientações (AUSTRUY, 1965; HIGGINS, 1959).

Os jogos da concorrência imperfeita ou monopolística (CHAMBERLIN, 1933 ; ROBINSON, 1940) não são sistematicamente considerados: a maioria dos pesquisadores ainda não mediu o papel da informação na vida econômica.

Críticas são levantadas contra a teoria da especialização internacional: ela trata de igualdade de chances num momento em que as distâncias entre os países se acentuam perigosamente (PERROUX, 1955). As reações mais intensas vêm das nações em vias de desenvolvimento. A deterioração dos termos de troca por elas sofrida entre 1953 e 1968 faz mais do que anular as transferências internacionais efetuadas a seu favor (PREBISCH, 1964). Todavia, as condenações são mais virulentas quando advém do marxismo. Para Marx, a emergência do capitalismo resultou da acumulação primitiva realizada entre 1500 e 1800 pela Europa às custas de todo o mundo. No início do século passado, a teoria do imperialismo de Lênin e Rosa Luxemburgo renova essa análise da exploração das periferias. Edificada sob tais bases, a teoria do desenvolvimento do subdesenvolvimento (FRANK, 1970) infelizmente, chega muito tarde - num momento em que os países do Extremo-Oriente conseguem suas decolagens! 
41 Alguns questionam os princípios da análise espacial empregados até então, distinguindo, nas distribuições estudadas, três níveis: (i) as realidades observáveis do espaço geográfico; (ii) as redes que as formam, instituídas pelas empresas; e (iii) os planos - um espaço de representação, portanto -, onde são elaborados estratégias e projetos de valorização (PERROUX, 1950). A idéia de que o espaço é produzido repousa sobre as mesmas bases (LEFEBVRE, 1974).

\section{Uma nova geografia econômica}

Tal como vinha sendo praticada desde os anos 1880 , os geógrafos rompem com essa geografia econômica e também com a geografia regional - sobretudo a descritiva, que esteve no coração da disciplina desde 1900. Eles se voltaram à teoria espacial e mergulharam com gosto nos modelos de von Thünen, Weber e Christaller.

Assim sendo, a nova geografia econômica confunde-se com a economia espacial, a quem deve grande parte de sua inspiração? Não, pois ela lança algo novo sobre as formas e as dinâmicas da organização espacial. No interior dos espaços nacionais, dois tipos de região se opõem (ULLMAN, 1958): as áreas centrais, caracterizadas por uma economia complexa onde agricultura intensiva, diferentes indústrias e serviços se acumulam (GEER, 1927); (ii) os espaços periféricos, especializados no fornecimento de matérias-primas e energia. As áreas centrais de economia complexa atraem as atividades graças às economias de escala autorizadas por sua acessibilidade (STEWART et WARNTZ, 1958; WARNTZ, 1964) e às economias externas geradas pela forte urbanização.

A Megalópolis, junção de grandes cidades que formam uma faixa contínua de Boston a Washington, assegura a articulação do conjunto dos Estados Unidos e do resto do mundo (GOTTMANN, 1961). Nelas, a acumulação resulta de economias externas devido à especialização nas áreas de comunicação, informação e direção de empresas.

Para a nova geografia econômica, a teoria clássica da especialização internacional não leva em consideração o progresso e sua tradução em economias de escalas e economias externas (CLAVAL, 1970). Existem ganhos também sobre os custos de comutação (WILLIAMSON, 1975; RENFREW, 1975; CLAVAL, 1977a; GUILLAUME, 1997; CRAGUE, 2004). Sua consideração permite, enfim, unificar a teoria da cidade e a teoria das redes urbanas, explicando a lógica dos lugares centrais (CLAVAL, 1981).

46 A nova geografia econômica é mais sensível que a teoria econômica espacial ao papel da informação e à dinâmica do progresso. Para serem plenamente reconhecidos, esses resultados precisavam ser formalizados; os economistas se encarregaram de fazê-lo a partir de 1980 (KRUGMAN, 1980, 1991; FUJITA et al., 1999).

\section{O espaço das outras ciências sociais}

47 Aos olhos de alguns economistas (TSURU, 1963), sociólogos (REMY, 1966), historiadores (LOPEZ, 1963) e especialistas em informação (MEIER, 1965), as cidades são essencialmente carrefours. Por muito tempo uma especialidade americana (GRAFEMEYER et JOSEPH, 1979), a sociologia urbana passou a interessar cada vez mais os europeus (REMY, 1966; LEDRUT, 1968), uma vez que o fim dos camponeses ajudava a compreender a especificidade das sociedades tradicionais (MENDRAS, 1967). 
48 A Antropologia concebe as sociedades que estuda como feitos de redes de relações institucionalizadas e codificadas. As gramáticas que elas elaboram não são as mesmas em todos os lugares (MAQUET, 1971). Às instituições das sociedades tradicionais, as sociedades modernas acrescentam burocracias e formas mais ou menos racionalizadas de autoridade (ETZIONI, 1964, 1968). Tal análise enfatiza a diversidade das formas nas quais o poder se reveste: a institucionalização tem por objetivo canalizar e controlar os aspectos por ele assumidos nos diferentes tipos de relações (CLAVAL, 1973, 1978). Já se percebe o surgimento da idéia de governança.

\section{Planejadores e urbanistas}

Planejadores e urbanistas estão frequentemente associados à origem da renovação do pensamento sobre as relações entre economia, sociedade e espaço entre 1940 e 1970.

As receitas que eles propõem são as mais diversas; eles se servem delas abundantemente. As ações que eles conduzem são exitosas. Todavia, eles descobrem que, progressivamente, suas receitas perdem eficácia. Elas funcionaram durante os Trinta Gloriosos, mas não repousavam sobre uma compreensão suficientemente sutil dos mecanismos atuantes no espaço social para continuarem valorizadas quando as condições da vida econômica mudaram - com o choque do petróleo e a liberação das trocas. Assim, assistimos a um segundo e profundo questionamento desde 1970, 1975.

\section{Uma segunda série de questionamentos}

51 Em trinta anos, a maneira como as Ciências Sociais e a Economia concebem o espaço muda rapidamente. A renovação do pensamento econômico ligado a Keynes se esgota: não é mais suficiente estimular a demanda para recuperar a economia.

52 Teses monetaristas fazem sucesso (FRIEDMAN, 1973). Os procedimentos que levam ao crescimento resultam da confiança que os agentes econômicos conferem à moeda. Não é mais ocasião de manipular sem cessar as taxas de juros! Para criar condições normais de concorrência e incitar a competição, a desregulamentação se impõe, caminhando junto com um "desarmamento" aduaneiro que estimula as trocas internacionais.

53 A partir dos anos 70, os postulados sobre os quais se assentavam as políticas praticadas desde a II Guerra Mundial são questionados. A partir de então, o slogan é edificar o desenvolvimento pela base (STÖHR, 1981)!

54 A passagem da economia de oferta - que dominava desde 1945 - a uma economia da demanda se confirma, tornando a concorrência mais viva e conduzindo as empresas a aprofundar a inovação.

\section{Progresso dos transportes e das telecomunicações, globalização, contra-urbanismo e metropolização}

As inovações no plano dos transportes e das comunicações se multiplicam no decorrer dos trinta anos que se seguem à II Guerra Mundial: revolução dos transportes de massa, contêiner para enviar os produtos fabricados, revolução dos transportes rápidos de pessoas (avião ou trem de grande velocidade), explosão das telecomunicações. 0 obstáculo da distância diminui, as economias se vêem próximas (Claval, 2003). Fim da 
geografia? Não: as distribuições são profundamente modificadas, porém distância e proximidade continuam com seus papéis - ainda que alterados.

O estabelecimento de contatos é essencial nos negócios e na vida das empresas (TÖRNQVIST, 1968, 1970). De agora em diante, durante o dia pode-se ir ao encontro de pessoas a $2000 \mathrm{~km}$, ao invés de $200 \mathrm{~km}$; em dois ou três dias, vai-se de um lado a outro do planeta!

As novas técnicas de comutação reduzem o número de centros pelos quais transitam as mensagens. Geralmente, dois níveis são suficientes: o que assegura as ligações locais e o que permite alcançar os correspondentes mais longínquos. As mensagens não são mais transmitidas sobre árvores hierarquizadas, mas sobre um labirinto de linhas onde computadores as conduzem ao itinerário menos carregado.

As revoluções técnicas dos transportes e das comunicações encurtam o mundo, reestruturando-o da seguinte forma: fim das hierarquias complexas! Isso é perceptível na organização das infra-estruturas de telecomunicação e na estrutura de redes destinadas aos contatos - os das cidades. Eles são reduzidos a dois níveis: o local e o que acessa o resto do mundo - o dos hubs de redes aéreas, que é, também, o das metrópoles (CLAVAL, 1987).

59 À medida em que a revolução dos transportes e das comunicações assegura, em todos os pontos, um acesso satisfatório às redes gerais de telecomunicações e de transportes rápidos, ela estimula a contra-urbanização. À medida em que os contatos urgentes entre parceiros distantes só se desenvolvem em centros importantes, ela conduz à metropolização (CLAVAL, 1987; LACOUR et PUISSANT, 1999). Doravante, as grandes cidades se beneficiam do essencial das vantagens antes reservadas às áreas centrais dos espaços nacionais. A metropolização põe em xeque a tendência à concentração anunciada com frequência nos anos 50 e que não cessaria de se acentuar. Cidades globais dominam a cena mundial (SASSEN, 1991).

Com a ampliação da facilidade de acesso às vantagens asseguradas pela metropolização, as atividades dos espaços periféricos torna-se igualmente mais fácil. A oposição entre espaços industrializados e espaços em vias de desenvolvimento é atenuada.

\section{As cadeias produtivas face à globalização}

61 Numa cadeia que produz artigos manufaturados, muitos segmentos se distinguem: no topo, o abastecimento das usinas em energia e em matérias-primas; no centro, a fase onde o artigo é elaborado, passando de ateliê em ateliê e de fábrica em fábrica; na parte inferior, a distribuição de bens ou serviços fabricados.

o segmento onde as atividades produtivas se situam exige numerosos controles, o que implica contatos diretos. Numa empresa, é difícil exigir quadros que se deslocam permanentemente. Eles aceitam fazê-lo sem reclamar quando isso ocorre durante a jornada.

63 Antes da revolução dos transportes rápidos, a parte das cadeias onde ocorriam as fabricações se inscrevia em espaços cujo raio não excedia o dos deslocamentos diários $250 \mathrm{~km}$. Isso dava aos Estados um poder considerável sobre as empresas.

A revolução das telecomunicações suprime certos controles (as máquinas computadorizadas podem ser manejadas à distância); graças aos transportes rápidos, o raio acessível em 24 horas passa de 250 a 1500 km (no mínimo) e, em uma semana, 10000 
ou $20000 \mathrm{~km}$. O segmento de fabricação das cadeias produtivas não se limita mais a um único Estado (CLAVAL, 1987). As empresas podem deslocar tal segmento se coerções inadmissíveis lhes forem impostas. A globalização provoca uma diminuição significativa do poder dos Estados sobre a economia.

\section{A passagem de uma economia dominada pela oferta a uma economia dominada pela demanda}

Todas as energias do mundo pós-guerra são voltadas à reconstrução. Tudo o que é produzido facilmente encontra comprador. A economia é dominada pela oferta.

A partir de 1970, as condições do mercado mudam. Grande parte da população já está equipada. Não se vive mais numa sociedade de penúria. Consumidores tornam-se mais exigentes. Cabe às empresas responder às suas expectativas! Não há mais como se contentar com um produto igual ao do vizinho! A demanda se diferencia. A concorrência se vivifica. A qualidade dos produtos torna-se argumento decisivo na venda.

Para permanecerem competitivas, doravante as empresas devem inovar permanentemente: a geografia econômica encontra-se em modificação. A busca da eficácia passa amiúde por reagrupar, em clusters, as atividades produtivas: efeito paradoxal da concorrência avivado pela globalização! R. Kloosterman et R. Boschma resumem da seguinte forma a mutação disso resultante:

"Analisando as fontes locais e regionais de inovação e aprendizagem, aspectos 'soft' como instituições, imersão, confiança, capital social e complexas formas de governança são explorados. Isso reformula o nexo entre o global e o local e, ao fazêlo, abala o mito da morte da distância" (BOSCHMA e KLOOSTERMAN, 2005, p. 393).

Daí em diante, os economistas levarão em consideração uma série de noções que, até então, tinham sido negligenciadas, tornando-se sensíveis ao papel da confiança; interrogando-se sobre o impacto do capital social sobre os desempenhos locais ou regionais; explorando as interdependências não-comerciáveis; e ligando-se às trocas tácitas de conhecimentos. Eles adotam formas de apreender o espaço que, até então, eram nomeadamente típicas de geógrafos regionais (as estruturas sociais locais), sociólogos (redes instituídas ou espontâneas de relações) ou politólogos (a imbricação dos jogos de poder e as formas de governança).

\section{A primeira fase do movimento: anos 1970 e início dos anos 1980}

Os anos 70 são os anos da desordem: o receituário proposto pela ciência regional desde meados dos anos 50 se mostra ineficaz. Conceber o desenvolvimento pela base? Sim, mas como?

70 A renovação incide sobre o conjunto das ciências sociais. O questionamento das abordagens econômicas praticadas até então não advém mais apenas do marxismo - que, enfim, toma consciência de suas lacunas em termos espaciais (LEFEBVRE, 1972; CLAVAL, 1977b) e começa a se reformar. Às vezes, à maneira de David Harvey, o questionamento ocorre mesmo permanecendo num quadro ortodoxo (HARVEY, 1982). Por repetidas vezes, o marxismo propõe uma teoria de duas velocidades (grande teoria e meso-teoria), que se aproveita dos métodos da ciência econômica para as situações corriqueiras mas trata de períodos de crise ou de ruptura fazendo referência ao modelo marxista. É o ponto de vista dos regulacionistas franceses (AGLIETTA, 1976; BOYER, 1986), dos geógrafos 
estruturacionistas (PRED, 1983; THRIFT, 1983) e dos sociólogos (GIDDENS, 1984). Nos países anglo-saxões, os estruturacionistas apóiam-se na geografia do tempo para chamar a atenção das estruturas intermediárias que constituem as regiões (HÄGERSTRAND, 1970). A geografia econômica tirará partido dessas idéias (SCOTT e STORPER, 1986).

71 Por sua vez, a Sociologia e a História concedem amplo espaço à idéia de progresso, e acentuam mais o papel do tempo do que o papel do espaço. Todavia, as atitudes mudam (LEPETIT, 1988). A crítica àquela idéia desemboca numa mutação epistemológica maior: a pós-modernidade (JAMESON, 1984, 1991). Doravante, os pesquisadores fixar-se-ão nos jogos de poder no espaço (LEFEBVRE, 1974; FOUCAULT, 1976), analisarão a ciência como o fariam com qualquer outro discurso (FOUCAULT, 1966) e tomam as técnicas de desconstrução à la Derrida (DERRIDA, 1967). É o tournant linguistique. As ciências sociais não acreditam mais nas grandes narrativas e estão mais modestas. Concedem espaço à subjetividade - a virada cultural - e mostram-se mais sensíveis às realidades locais - a virada espacial (CLAVAL, 2007).

A economia geográfica assume uma forma moderna (KRUGMAN, 1980 ; 1991 ; FUJITA et al., 1999). Ela leva em consideração a mobilidade de bens e a dos fatores de produção ao mesmo tempo. 0 modelo de Dixit-Stiglitz-Krugman explica o comércio inter-regional. Tendo por complemento os modelos de gravitação e o jogo dos custos de transferência, a economia geográfica reconhece as estruturas centro-periferia e mostra como as desigualdades regionais evoluem. Os modelos clássicos da concorrência espacial - os de Hotelling et de Cournot - completam o quadro. Assim, ela está em condições de explicar a amplitude e os determinantes desta concorrência. Tal como elaborada há trinta anos, a economia geográfica privilegia as "dimensões macroespaciais, deixando de lado os aspectos microespaciais porém suscetíveis de jogar um papel de relevo nos fenômenos estudados" (COMBES et al., 2006, p. 381).

73 Analisar a firma como uma organização - no sentido sociológico do termo - leva a abordar o estudo das redes sob um novo ângulo: seu funcionamento reflete o jogo das distâncias sociais; ele é tão mais eficaz quando se desenvolve num clima de confiança. A reflexão regional deve, portanto, apelar à Sociologia, à Antropologia ou às Ciências Políticas.

74 É desta efervescência de reflexão teórica que surgem os desenvolvimentos que irão se impor nos anos 1980 e dominarão os anos 1990.

\section{0 novo regionalismo (new regionalism)}

Nos anos 1980 o caminho torna-se mais preciso. Pesquisadores italianos analisam o dinamismo de distritos industriais da Terceira Itália e o papel nela jogado por pequenas e médias empresas (BAGNASCO, 1977; GAROFOLI, 1983; BECATTINI, 1987, 1989; CAMAGNI, 1991). Isso nos remete à atualização das análises de Marshall. Atenta-se a trabalhos franceses que mostram a permanência desse tipo de estrutura até hoje (HOUSSEL, 1978).

Em 1984, Philippe Aydalot funda o GREMI, atual GERI (Grupo de Estudo e Pesquisa sobre Inovação), que reagrupa investigadores franceses, suíços e italianos (AYDALOT, 1976, 1986; MAILLAT et PERRIN, 1992). Sua ação é próxima da de holandeses como Jan Lambooy (1984). Para eles, o dinamismo local deriva da presença de ambientes inovadores, onde tentam explicar sua gênese e seu funcionamento - sobre os ambientes inovadores, ver também Asheim e Braczyk et al. (ASHEIM, 1996; BRACZYK et al, 1998). 
77 Ao mesmo tempo, geógrafos californianos se aproveitam simultaneamente de trabalhos acerca de distritos industriais e do papel das trocas na vida econômica (Scott et STORPER, 1986). Pesquisas paralelas são levadas adiante no mundo anglo-saxão por Piore e Sabel (PIORE e SABEL, 1984). Tudo isso gira ao redor dos clusters de atividades (PORTER, 1990).

78 As pesquisas sobre esses temas se multiplicam. A equipe de Grenoble animada por Pecqueur e Courlet (em colaboração com a de J.-P. Gilly em Toulouse) fala, antes, em Sistemas Produtivos Locais (PECQUEUR, 1992, 1996; COURLET et PECQUEUR, 1992; COURLET et DIMOU, 1992; COURLET, 2001). Courlet identifica 220 deles na França.

79 A evolução parece clara: o modo fordista de acumulação, fundado sobre economias de escala (economies of scale) que permitem à grande empresa entregar um produto único, cede lugar ao modo pós-fordista, construído sobre economias de perspectivas (economies of scope) que, para se impor, atuam sobre as transformações de diferentes tipos de produtos (BOSCHMA et KLOOSTERMAN, 2005, p. 392). Neste mundo pós-fordista, a proximidade assume papel essencial: ela conduz à instauração de um clima de confiança e à elaboração do capital social constituído pelas redes de relações já estabelecidas (embeddedness); através delas, são as interdependências não-comerciáveis que influem sobre os resultados da gestão. Em um ambiente restrito onde reina a confiança, as trocas implícitas de conhecimentos possuem lugar de primeira grandeza.

80 A essa interpretação em termos de transformação da demanda opõem-se outras, que não consideram a demanda como determinante (BENKO e LIPIETZ, 1992, 2000). Na visão regulacionista, a necessidade de manter a remuneração dos fatores conduz os empreendedores a tirar partido dos pools de mão-de-obra - cujos salários são flexíveis (LIPIETZ, 2000). Os distritos também podem ser explicados por razões puramente mercantis (SCOTT e STORPER, 1986, aproveitando-se de COASE, 1937, e WILLIAMSON, 1976).

81 Entretanto, a maioria dos autores insiste mesmo sobre as transformações da demanda. Assim, eles mostram como o local e o regional podem ser fatores de dinamismo e conduzirem à formação de núcleos e clusters empresariais, distritos industriais, sistemas produtivos locais, ambientes de inovação. Tais noções são vizinhas e se sobrepõem um pouco. A formação de agrupamentos locais resulta de um certo número de mecanismos que explicitamos. É assim que se afina a idéia de externalidade: às externalidades marshallianas, conhecidas há muito tempo, são acrescidas as de Jacobs, Arrow e Romer.

82 A novidade desses trabalhos deve-se à atenção enfim concedida ao conhecimento. 0 espaço não é mais simplesmente atravessado por fluxos de informação, mas sim pontuado por lugares onde a memória se acumula, onde conhecimentos são criados e se perpetuam. Quais ingredientes ainda estarão por vir?

\section{Desde o fim dos anos 1990: as críticas ao novo regionalismo}

83 Distritos industriais, clusters empresariais, sistemas produtivos locais e ambientes de inovação fornecem aos governos confrontados com a desindustrialização novos esquemas de intervenção. Ao invés de enfatizar as grandes empresas, por quê não apostar nas PME ${ }^{1}$ se eles se mostram mais dinâmicas? Por quê não tirar partido dos distritos existentes para ajudá-las, fornecer novos financiamentos e insuflar suas capacidades inovadoras? dos sistemas produtivos locais, sua evolução recente e seu dinamismo atual (DATAR, 
2001). O INSEE ${ }^{3}$ contribui recenseando 700 aglomerações de estabelecimentos especializados - onde pouco menos que a metade funcionava como sistemas produtivos locais (GENEAU de LAMARLIÈRE, 2001).

Críticas não faltam. Distritos, clusters empreendedores ou sistemas produtivos locais não são realidades fixas; eles são afetados pela globalização, que nem sempre lhe são favoráveis.

Modelos próximos aos do distrito industrial, de sistemas locais de produção, da região de aprendizagem, de ambientes de inovação ou de sistemas enraizados (embeddedness) não consideram muito as relações extra-locais travadas por todas essas unidades - relações que a evolução recente multiplicou. Com a globalização, os lugares não são mais separados dos níveis superiores por uma série de intermediários atuando como empecilho; eles vivem ao ritmo das mutações globais (MASSEY e JESS, 1995). Fala-se de glocalização. Nela, a natureza dos territórios é modificada.

\section{Uma dupla reflexão sobre a natureza dos territórios e sobre a natureza das informações relevantes para o domínio econômico}

87 A bifurcação contemporânea das abordagens regionais decorre de uma nova reflexão sobre a natureza da informação mobilizada pela vida econômica, bem como acerca da natureza dos espaços de pequena dimensão.

Antes, os economistas concebiam a informação como um conjunto não-estruturado de mensagens independentes, contentando-se em estudar os custos de transferência de um suporte a outro, de um indivíduo a outro, de um lugar a outro. Porém, a informação é organizada. Aquela que interessa à empresa é feita (i) de novidades do mercado; (ii) de savoir-faire que devem orientar os trabalhadores que elaboram as ferramentas; (iii) de conhecimentos técnicos que permitem conceber e produzir máquinas e equipamentos; (iv) de saberes científicos que ajudam engenheiros a inventarem novos procedimentos e produtos; (v) de saberes sociais estruturados pelas empresas; (vi) de conhecimentos relativos a mercados, clientela e publicidade; (vii) de savoir-faire logísticos que se desenvolvem após uma geração.

Estudar o espaço econômico é mensurar das exigências espaciais próprias à transmissão e à expansão desses diferentes tipos de saber; é medir o impacto das novas tecnologias de informação e de comunicação sobre seu dinamismo (CASTELLS, 1996 ; SCOTT, 2000).

O espaço deixa de ser concebido apenas como um suporte, uma coleção de fatores de produção, um obstáculo à vida de relações, um conjunto de redes que canalisa homens, produtos e informações. Ele é feito de esferas mentais: algumas delas estão estreitamente localizadas, enquanto outras podem dilatar-se à escala planetária. As que possuem pequenas dimensões dão ao espaço que elas equipam estruturas originais, cuja pertinência tem sido descoberta pela pesquisa econômica contemporânea. Quando falamos de territórios, pensamos hoje nas realidades materiais, sociais e ideais ao mesmo tempo.

91 A hipótese da planície de transporte não é útil senão para apreender a fatia do real onde atuam as fricções provocadas pela distância. A realidade espacial tem outras dimensões. Ela é organizada pela vida social e econômica que nela se desenvolve.

No final do século XIX, os geógrafos descobriram a existência de estruturas espaciais: as regiões. O espaço não era um simples suporte, um ingrediente pouco negligenciável de 
combinações cujos elementos essenciais se situavam alhures. Ele constituía uma dimensão essencial da vida coletiva. No espaço, esboçavam-se conjuntos que estruturavam tanto as relações tecidas em seu interior quanto aquelas nutridas pelo exterior. A região não era uma entidade isolada do resto do mundo: ela fazia parte de um todo de onde retirava sua substância, extraía os bens que lhe faltavam e as idéias que a alimentavam - e que, a seu turno, ela irrigava.

Hoje, essa visão sobre a região é designada pelo termo território. A atual mutação da ciência regional procede do enriquecimento da noção de espaço que ela mobiliza - esse espaço que é natureza e cultura, superfície e redes, realidade tangível e representações, obra coletiva e experiência pessoal, extensão livre e apropriada ao mesmo tempo.

\section{Conclusão}

94 As ciências do homem e da sociedade experimentaram a dificuldade de pensar o espaço. Durante muito tempo, a maior parte das disciplinas preocupou-se mais com a duração, portadora de mecanismos e de explicações, do que com a extensão, concebida como estática.

Entre os anos 1810 e 1920 elabora-se um primeiro conjunto de análises espaciais, ainda que restrito a um pequeno número de disciplinas (Economia, Geografia, Planejamento). As interações entre essas correntes de pensamento são quase nulas.

96 A Grande Crise e a II Guerra Mundial modificam as atitudes : os governos não podem tolerar o agravamento das desigualdades entre nações ou entre regiões. Os estudos regionais beneficiam-se de trabalhos sobre os efeitos multiplicadores do investimento e do comércio exterior. A análise das redes urbanas torna-se sistemática. A consideração das economias externas e das economias de escala se generaliza.

97 A terceira fase começa nos anos 1970, no momento em que receituários inspirados pela macroeconomia perdem eficácia. A mundialização se acelera graças à revolução dos transportes rápidos e à revolução das telecomunicações. A distância pesa menos, mas pontos de reagrupamento e de condensação aparecem. De uma parte, metrópoles; de outro, clusters, distritos industriais, regiões de inovação. As economias de informação, comunicação e conhecimento são sublinhadas.

O que nos ensina o quadro que acabamos de esboçar? Cada disciplina permanece fiel aos seus modos de apresentação e de raciocínio (Geneau de LAMARLIÈRE et STASZAK, 2000). Porém, criou-se um campo interdisciplinar que versa sobre a maneira como o espaço é compreendido. Até os anos 1950, o espaço era o suporte da produção e do consumo e obstáculo à movimentação de bens. Os anos 50 e 60 aprendem a analisá-lo em termos de pólos e redes, bem como a considerar o freio provocado pela distância à difusão de informações. Os trinta últimos anos enfatizam essa evolução: os transportes são menos onerosos, o que aumenta a competitividade; para subsistir, as empresas devem inovar. Não é mais a transmissão de informações estandartizadas que é necessário levar em conta, mas a transmissão de conhecimentos estruturados - em que uma parte continua a depender de relações face-a-face, de contatos diretos.

99 Hoje, todas as disciplinas apreendem o espaço a partir de um corpo comum de hipóteses concernentes à sua natureza e organização - como mostram a atenção dada à economia de proximidade (PECQUEUR et ZIMMERMANN, 2004 ; LAGENDIJK et OINAS, 2005), aos 
distritos industriais, às sequências de empresas, às regiões de inovação, aos sistemas produtivos locais etc.

\section{BIBLIOGRAPHY}

AGLIETTA, M. Régulation et crises du capitalisme. Paris, Calmann-Lévy, 1976.

ALONSO, W. Location and Land Use: toward a General Theory of Land Rent. Cambridge, Harvard University Press, 1964.

ANDRÉE, K. Geographie des Welthandels mit geschichtlichen Erlaüterungen. Stuttgart, 2 vol, 1861-1874.

ASHEIM, B.T. "Industrial districts as 'learning regions'. A condition for prosperity", European Planning Studies, vol. 4, n 4, p. 379-400, 1996.

AURAY, J.-P, BAILLY, A., DERYCKE, P.-H., HURIOT, J.-M. (eds.). Encyclopédie d'économie spatiale, Paris, Economica.), 1994.

AUSTRUY, J., Le Scandale du développement. Paris, Rivière, 1965.

AYDALOT, P. Dynamique spatiale et développement inégal. Paris, Economica, 1976.

(ed.). Milieux innovateurs en Europe. Paris, GREMI, 1986.

BAGNASCO, A. Tre Italia. La problematica territoriale dello sviluppo italiano. Bologne, Il Mulino, 1977.

BECATTINI, G. (dir.). Mercato e forze locali : il distritto industriale. Bologne, Il Mulino, 1987.

-. Modeli locali de sviluppo. Milan, Il Mulino, 1991.

BENKO, G., LIPIETZ, A. (eds.). Les Régions qui gagnent. Districts et réseaux : les nouveaux paradigmes de la géographie économique. Paris, PUF, 1992.

(eds). La Richesse des régions. La nouvelle géographie socio-économique. Paris, PUF, 2000.

BERDOULAY, V., CLAVAL, P. (eds.). Aux débuts de l'urbanisme français. Paris, L'Harmattan, 2001.

BERRY, B. J. L. "Cities as systems within systems of cities", Papers of the Regional Science Association, vol. 13, p. 147-183, 1964.

-------, HORTON, F. E. Geographic Perspectives on Urban Systems. Englewood Cliffs, Prentice-Hall, 1970.

BOSCHMA, R. et KLOOSTERMAN, R. C. (eds.). Learning from Clusters. A Critical Assessment from an Economic-Geographic Perspective. Dordrecht, Springer, 2005.

BOUDEVILLE, J-R. Les Espaces économiques. Paris, PUF, 1961.

. Les Programmes économiques. Paris, PUF, 1963.

. Problems of Regional Economic Planning. Edimbourg, Edinburgh University Press, 1966.

(ed.). L'Espace et les pôles de croissance. Paris, PUF, 232 p., 1968.

-. Le Sens pratique. Paris, Editions de Minuit, 1980.

BOYER, R. La Théorie de la régulation. Une étude critique. Paris, la Découverte, 1986. 
BRACZYK, H., COOKE, P; HEIDENREICH, M. (eds.). Regional Innovations Systems. Londres, University College London Press, 1998.

BUCHANAN, R. O. The Pastoral Industry in New Zealand. Londres, Institute of British Geographers, 1935.

CAMAGNI, R. (ed.). Innovation Networks. Spatial Perspectives. Londres, Bellhaven, 1991.

CASTELLS, M. The Rise of the Network Society. Londres, Blackwell, 1996.

CHAMBERLIN, E. H. The Theory of Monopolistic Competition. Cambridge, Harvard University Press, 1933.

CHARDONNET, J. Les Grands Types de complexes industriels. Paris, A. Colin, 1953.

CHISHOLM, G.Handbook of Commercial Geography. Londres, Longman., 1953.

CHRISTALLER, W. Die zentralen Orte in Süddeutschland, Iéna, G. Fischer, 1933.; trad. ang., Central Places in Southern Germany, Englewood Cliffs, Prentice-Hall, 1966.

CLAVAL, P. Régions, nations, grands espaces. Géographie générale des ensembles territoriaux. Paris, Marie-Thérèse Genin, 1968.

--------. Les Relations internationales. Paris, Scodel, 1970.

--------. Principes de géographie sociale. Paris, Marie-Thérèse Genin et Litec, 1973.

"Les réseaux de circulation et l'organisation de l'espace : les fondements théoriques de la région polarisée", p. 355-364, 1977a de : Transports et voies de communication, Colloque de Dijon , 14-15 mars 1976, Dijon, Association Universitaire de l'Est, 1977.

--------."Le marxisme et l'espace", L'Espace Géographique, vol. 6, n 3, avril 1977, p. 145-154, $1977 b$.

--------. Espace et pouvoir. Paris, PUF, 1978.

--------. La Logique des villes. Introduction à l'urbanologie. Paris, Librairies Techniques, 1981.

. "La métropolisation de l'économie et de la société nord-américaine", Historiens et Géographes, n 312, déc. 1986-janv. 1987, 1987, p. 447-460, 1987.

. Histoire de la géographie française de 1870 à nos jours. Paris, Nathan, 1998.

- La Géographie du XXIe siècle. Paris, l'Harmattan, 2003.

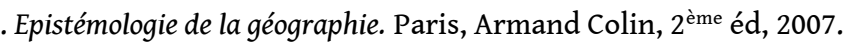

COASE, R. H. "The nature of the firm", Economica, vol. 4, n 16, p. 386-405, 1937.

COMBES, P.-Ph., T. MAYER et J.-F. THISSE. Economie géographique. L'intégration des régions et des nations, Paris, Economica, 2006.

COURLET, C. "Les systèmes productifs locaux : de la définition au modèle" in : DATAR, Réseaux d'entreprises et territoires. Regards sur les systèmes productifs locaux. Paris, La Documentation Française, p. 17-61, 2001.

; DIMOU, M. "Les systèmes productifs localisés : une approche dynamique longue" in : Economie industrielle et spatiale. Paris, Economica, 1995.

; PECQUEUR, B. "Les systèmes industriels localisés en France : un nouveau modèle de développement, in G. Benko, A. Lipietz (eds.), Les Régions qui gagnent. Paris, PUF, p. 81-102, 1992. 
CRAGUE, G. "Commutation. Essai sur l'économie de l'agglomération", Géographie, Economie, Societé, vol. 6, $\mathrm{n}^{\circ} 1$, p. 9-21, 2004.

DATAR. Réseaux d'entreprises et territoires. Regards sur les systèmes productifs locaux. Paris, La Documentation Française, p. 17-61, 2001.

DAVIES, O. A., WHINSTON, A. "Externalities, welfare and the theory of games", Journal of Political Economy, vol. 70, p. 241-262, 1962.

. "The economics of complex systems : the case of municipal zoning", Kyklos, vol. 27, p. 419-446, 1964.

DERRIDA, J. L'Ecriture et la différence. Paris, Seuil, 1967.

DOCKES, P. L'Espace dans la pensée économique du XVIe au XVIIIe siècle. Paris, Flammarion, 1969.

DUBOIS, M., KERGOMARD, J.-G. Précis de géographie économique. Paris, Masson, 1897.

DURKHEIM, E. La Division du travail social. Essai sur l'organisation des sociétés supérieures. Paris, Alcan, 1893.

ETZIONI, Amitai. Modern Organizations. Englewood Cliffs, Prentice-Hall, 1964.

--------.The Active Society. A Theory of Societal and Political Processes. New York, The Free Press, 1968.

FAVRE, P. Naissance de la science politique en France. Paris, Fayard, 1989.

FOUCAULT, M. Les Mots et les Choses. Paris, Gallimard, 1966.

Surveiller et punir. Paris, Gallimard, 1976.

FRANK, G. Le Développement du sous-développement. Paris, Maspéro, 1970.

FRIEDMAN, M. Studies in the Quantity Theory of Money. Chicago, Chicago University Press, 1973.

FRIEDRICH, E. "Wesen un geographisches Verbreitung der Raubwirtschaft", Pettermann's

Mitteilungen, $\mathrm{n}^{\circ}$ 3, p. 68-79 et $\mathrm{n}^{\circ}$ 4, p. 92-95, 1904.

FUJITA, M., KRUGMAN, P., VENABLES, Anthony J. The Spatial Economy. Cities, Regions and International Trade. Cambridge, The M.I.T. Press, 1999.

GALLOIS, L. Régions naturelles et noms de pays. Paris, Armand Colin, 1908.

GAROFOLI, G. Industrializzazione diffuse in Lombardia. Sviluppo territoriale e sistemi produttivi locali. Milano, Franco Angeli, 1983.

GEDDES, P. Cities in Evolution. An Introduction to the Town Planning Movement and to the Study of Civics. Londres, Williams and Norgate , 1915; trad. fse, L'Evolution des villes. Paris,Temenos, 1994.

GEER, S. de. "The American manufacturing belt", Geografiska Annaler, vol. 9, p. 233-259, 1927.

GENEAU de la MARLIERE, I. Les Théories du développement local en France. Texte inédit communiqué par l'auteur, 2001.

., STASZAK, J.-F. Principes de géographie économique. Paris, Bréal, 2000.

GEORGE, P. Géographie de l'énergie. Paris, Marie-Thérèse Genin, 1950.

GIBERT, A. La Porte de Bourgogne et d'Alsace (Trouée de Belfort) : étude géographique. Besançon, Jacques et Demontrond, 1930.

GIDDENS, A. The Constitution of Society. Outline of the Theory of Structuration, Cambridge, Polity Press, , 1984, trad. fse, La Constitution de la société. Paris, PUF, 1987, 474 p. 
GODLEWSKA, A. Geography Unbound. French Geographic Science from Cassini to Humboldt. Chicago, Chicago University Press, 1999.

GOTTMANN, J. Megalopolis. The Urbanized Seaboard of the United States. Cambridge, M.I.T. Press, 1961.

, SESTINI, A., TULIPPE, O., WILLATTS, E. C. et VILA, M. A. L'Aménagement de l'espace. Planification régionale et géographie. Paris, Armand Colin, 1952.

GÖTZ,W. "Die Aufgabe der "wirtschaftlichen Geographie (Handelsgeographie)", Zeitschrift der Gesellschaft zur Erdkunde zu Berlin, vol. 17, 1882, p. 354-388.

GRAFMEYER, Y, JOSEPH, I. (eds.). L'Ecole de Chicago. Naissance de l'écologie urbaine. Paris, Editions du Champ Urbain, 1979.

GUILLAUME, M. "Articulation entre les échanges immatériels : présentation", in A. OBADIA (ed.), Entreprendre la ville. Nouvelles temporalités, nouveaux services. La Tour d'Aigues, Editions de l'Aube, 1997, p. 229-233.

HÄGERSTRAND, T., 1970, "What about People in Regional Science", Papers of the Regional Science Association, vol. 24, p. 7-21.

HALBWACHS, M., 1925, Les Cadres sociaux de la mémoire. Paris, Albin Michel.

--------."Chicago, expérience ethnique", Annales d'histoire économique et sociale, vol. 4, p. 547-570, 1932.

-------. Morphologie sociale. Paris, A. Colin, 1938.

. La Topographie légendaire des évangiles en Terre Sainte. Essai sur la mémoire collective. Paris, PUF, 1941.

HARVEY, D. The Limits to Capital. Oxford, Blackwell, 1982.

HECKSCHER, E. "The effect of foreign trade on the distribution of income", 1949 [1919]. In : American Economic Association, Readings in the Theory of International Trade, Philadelphie, Blakiston, p. 272-300; ed. or suédoise, 1919.

HIGGINS, B. Economic Development. Principles, Problems and Policies. New York, Norton, 1959.

HOTELLING, H. "Stability in competition", Economic Journal, vol. 39, 1929, p. 41-57.

HOUSSEL, J.-P. Le Roannais et le Haut-Beaujolais. Un espace à l'écart des métropoles, Lyon, Presses Universitaires de Lyon, 1978.

ISARD, W. "Interregional and regional input-output analysis : a model of space economy", Review of Economics and Statistics, vol. 33, 1951, 318-328.

. Location and Space Economy. New York et Cambridge, John Wiley and MIT Press, 1956.

JAMESON, F. "Postmodernism or the cultural logic of late capitalism", New Left Review, n 146, 1984, p. 53-92.

--------. Postmodernism or the cultural logic of late capitalism. Londres: Verso, 1991.

JONES, R. A. "La science positive de la morale en France : les sources allemandes de 'La Division du travail social'", in Ph. BESNARD, M. BORLANDI, P. VOGT (eds.), Division du travail et lien social. Durkheim un siècle après. Paris, PUF, 1993, p. 11-41.

KEYNES, J. M. The General Theory of Employment, Interest and Money. Londres, Macmillan, 1936. 
KRUGMAN, P. R. "Scale economics, product differenciation and the pattern of trade", American Economic Review, vol. 70, 1980, p. 950-959.

."Increasing returns and economic geography", Journal of Political Economy, vol. 99, 1991, p. $483-499$.

LACOUR, C., PUISSANT, S. (eds.). La Métropolisation. Croissance, diversité, fractures. Paris, Anthropos, 1999.

LAGENDIJK, A. et OINAS, P. (eds.). Proximity, Distance and Diversity : Issues on Economic and Local Development. Aldershot, Ahsgate, 2005.

LAMBOOY, J. "The regional ecology of technical change" in J. Lambooy (ed.), New Spatial Dynamics and European Crisis. Tampere, Finnpublishers, 1984.

LAUNHARDT, W. "Die Bestimmung der zweckmassigsten Standortes einer gewerblichen Anlage", Zeitschrift des Vereins Deutscher Ingenieure, vol. 26, 1882, p. 106-115.

LEDRUT, R. Sociologie urbaine. Paris, PUF, 1968.

LEFEBVRE, H. Le Marxisme et la ville. Paris, Calmann-Lévy, 1972.

--------. La Production de l'espace. Paris, Anthropos, 1974.

LEPETIT, B. Les Villes dans la France moderne (1740-1840). Paris, Albin Michel, 1988.

LEVEN, C. L. Growth and Non-Growth in Metropolitan Areas and the Emergence of Polycentric Metropolitan Form. Saint-Louis, Washington University, Institute for Urban and Regional Studies, 1977.

LOPEZ, R. S. "The crossroads within the wall", in : HANDLIN, O., BURCHARD, J. (eds.). The Historian and the City. Cambridge, M.I.T. Press, , 1963, p. 27-43.

LÖSCH, A. "Beitrage zur Standort Theorie", Schmollers Jb Gesetzgebg. Verw. Volksw., vol 62, 1938, p. 329-335.

--------. Die raümliche Ordnung der Wirstschaft. Iéna, G. Fischer, 1940.

MAILLAT, D, PERRIN, J.-C. (eds.). Entreprises innovatrices et développement territorial. Neuchâtel, EDES, 1992.

MAQUET, A. Pouvoir et société en Afrique. Paris, Hachette, 1971.

MARCEL, J.-Ch. Le Durkheimisme dans l'entre-deux-guerres. Paris, PUF, 2001.

MARSHALL, A. Principles of Economies. Londres, Macmillan, 1890.

MASSEY, D. et JESS, P. (eds.). A Place in the World ? Places, Cultures and Globalization, Oxford, Open University, 1995.

MAUSS, M. et BEULAT, H. "Essai sur les variations saisonnières des sociétés eskimos. Essai de morphologie sociale", L'Année sociologique, vol. 9, , 1904/1905, p. 39-112.

MEIER, R. A Communication Theory of Urban Growth. Cambridge (Mass.), The M.I.T. Press, 1965.

MENDRAS, H. La fin des paysans. Paris, SEDES, 1967.

MUMFORD, L. A Story of Utopias. New York, Boni et Liveright, 1922.

OHLIN, B. Interregional and International Trade. Cambridge, Harvard University Press, 1933.

PECQUEUR, B. (ed.). Dynamiques territoriales et mutations économiques. Paris, L'Harmattan, 1996.

--------. Le Développement local. Paris, Syros, 1989. 
, ZIMMERMANN, J. B. (eds.). Economie de proximités. Paris, Hermés-Lavoisier, 2004.

Perrin, M. La Région industrielle de Saint-Etienne. Etude de géographie économique. Tours, Arrault, 1937.

PERROUX, F. "Les espaces économiques", Economie appliquée, vol. 3, , 1950, p. 225 sqq. Repris aux p. 12141 de F. PERROUX. L'Economie du XXe siècle. Paris, PUF, 1961.

"La notion de pôle de croissance", Economie appliquée, vol. 8, 1955, p. 307 sqq. Repris aux p. 142-144 de F. PERROUX, L'Economie du XXe siècle. Paris, PUF, 1961.

PHLIPPONNEAU, M. "Vauban et la géographie appliquée au Canada", Mélanges géographiques offerts à Raoul Blanchard, Québec, 1959.

PIORE, M. J., SABEL, C.F. The Second Industrial Divide. Possibilities for Prosperity. New York, Basic Books, 1984.

PONSARD, C. Economie et espace, Paris, SEDES, 1955.

Histoire des théories économiques spatiales, Paris, Armand Colin, 1958.

PORTER, P. The Competitive Advantage of Nations, New York, Free Press, 1990.

PREBISCH, R. Towards a New Trade Policy for Development, New York, United Nations, 1964.

PRED, A. "Structuration and place : on the becoming of sense of place and structure of feeling", Journal of Theory of Social Behaviour, vol. 13, 1983, p. 45-68.

REMY, J. La Ville, phénomène économique, Paris, les Editions ouvrières, 1966.

RENFREW, C. "Trade at a distance : questions of integration and communication", in : J. A. SABLOFF et C. D. IAMBERG-kARKOWSKY (eds.), Ancient Civilization and Trade, Albuquerque, Universit of New Mexico Press, 1975, p. 3-59.

RICARDO, D., 1817, The Principles of Political Economy and Taxation, Londres.

RITTER, C., 1974 [1852], Introduction à la géographie générale comparée, Paris, les Belles Lettres ; éd. or. allemande, Berlin.

ROBINSON, J. Economics of Imperfect Competition, Londres, Macmillan, 1940.

SAMUELSON, P. "International trade and the equalization of factor prices", Economic Journal, vol. 58,1948 , p. $163-184$

."International factor-price equalization once again", Economic Journal, vol. 59, 1949, p. 181-197.

SASSEN, S. The Global City : London, New York, Tokyo. Princeton, University of Princeton Press, 1991.

SAUSHKIN, J. C. "Large areal complexes of productive forces in the Soviet Union", Papers and Proceedings of the Regional Science Association, vol. 8, 1962, p. 93-104.

SCITOVSKY, T. "Two concepts of external economies", Journal of Political Economy, vol. 62, 1954, p. 143-151.

SCOTT, A. J. The Cultural Economy of Cities : Essays on the Geography of Image-Producing Industries, Londres, Thousand Oaks, 2000.

; STORPER, M. (eds.). Production, Work, Territory. The Geographical Anatomy of Industrial Capitalism, Boston, Allen and Unwin, 1986.

SIEGFRIED, A. Tableau de la géographie politique de la France de l'Ouest, Paris, A. Colin, 1913. 
SMITH, A. The Wealth of Nations, 1776.

STEWART, J. Q., WARNTZ, W. "Physics of population distribution", Journal of Regional Science, vol. 1, 1958, p. 119-121.

STÖHR, W. "Development from below : the bottom-up and periphery-inward development paradigm", 1981. In: STÖHR, W., TAYLOR, D.R.F (eds). Development from above or below? The Dialectis of Regional Planning in Developing Countries, Chichester, Wiley, 1981.

STORPER, M. The Regional World. Territorial Development in a Global Economy. New York, Guilford Press, 1997.

THRIFT, N. J. "On the determination of social action in space and time", Environment and Planning D- Society and Space, vol. 1, 1983, p. 23-58.

THÜNEN, J.-H. Von. Der isolierte Staat in Beziehung auf Landwirtschaft und Nationalökonomie, Hambourg, Perthes, 1826.

TÖNNIES, F. Communauté et société. Paris : PUF, 1944 (1887).

TÖRNQVIST, G. Flows of Information and the Location of Economic Activitives. Lund: Gleerup, 1968.

--------. Contact Systems and Regional Development. Lund: Glerrup, 1970.

TSURU, S. "The economic significance of cites". In : HANDLIN, O., BURCHARD, J. (eds.). The Historian and the City. Cambridge: M.I.T. Press, 1963, p. 44-55.

ULLMAN, E. L. "Regional development and the geography of concentration", Papers and Proceedings of the Regional Science Association, vol. 4, p. 179-198, 1958.

VANCE, J. E. Jr. Geography and Urban Evolution in the San Francisco Bay Area. Berkeley, University of California Press, 1964.

VIDAL de la BLACHE, P. Des divisions fondamentales du sol français. Bulletin littéraire, vol. 2, 1888, p. 1-17.

--------. Tableau de la géographie de la France. Paris, Hachette, 1903.

--------. "Les pays de France", Réforme sociale, vol. 48, nº 8, 1904, p. 333-344.

--------. "Régions françaises", Revue de Paris, n 6, 1910, p. 821-849.

WARNTZ, W. "A new map of the surface of population potentials for the United States in 1960", Geographical Review, vol. 54, 1964, p. 170-18

WEBER, A. Uber den Standort der Industrien. Tübingen, 1909.

. Economie et société. Paris, Plon, 1971.

. Euvres politiques (1895-1919). Paris, A. Michel, 2004.

WILLIAMSON, O. E. Markets and Hierarchies. New York, The Free Press, 1975.

YOUNG, A. "Increasing returns and economic progress", Economic Journal, vol. 38, 1928, p. 527-542.

\section{NOTES}

1. Pequenas e médias empresas (N.T.).

2. Departamento Interministerial para o Planejamento do Território e a Atratividade Regional (N.T.).

3. Instituto Nacional de Estatística e Estudos Econômicos (N.T.). 


\section{ABSTRACTS}

$\mathrm{Na}$ reflexão concernente ao espaço e ao território, pode-se distinguir três fases: (1) do início do século XIX ao entre-guerras, este domínio é abordado por apenas três disciplinas: teoria econômica espacial, teoria das trocas internacionais e geografia econômica (primeira fase). Elas não se relacionam; (2) de 1930 a 1970, o descobrimento do desenvolvimento desigual conduz todas as Ciências Sociais a um interesse pela organização espacial. A fundação da ciência regional, a exploração de mecanismos macroeconômicos e uma nova curiosidade pelas economias externas e de escala aproximam economia, geografia econômica (segunda fase) e planejamento; (3) desde 1970, a falência das políticas desenvolvidas nos anos 1950 e 1960 levou a uma profunda mudança de perspectiva: atualmente, as pessoas enfatizam o desenvolvimento pela base, o papel dos clusters e a economia do conhecimento.

Three phases may be distinguished in the reflection concerning space and territory. 1- From the beginning of the nineteenth century to the interwar period, this field was explored by three disciplines, spatial economic theory, international trade theory and economic geography (first style). There were no relations between them. 2- From 1930 to 1970, the discovery of unequal development led all social sciences to develop an interest in spatial organization. The foundation of regional science, the exploration of macroeconomic mechanisms and a new curiosity for scale and external economies made closer economics, economic geography (second style) and planning. 3- Since 1970, the failure of the policies developed in the 50 s and 60 s was conducive to a deep change of perspective: people now stress the development from below, the role of clusters and the economy of knowledge.

Trois phases se distinguent dans la réflexion sur l'espace et le territoire 1- Du début du XIXe siècle à l'entre-deux-guerres, le domaine n'est abordé que par trois disciplines, la théorie économique spatiale, la théorie de l'échange internationale et la géographie économique première manière. Elles n'ont pas de rapports entre elles. 2- De 1930 à 1970, le développement inégal conduit la plupart des sciences sociales à s'intéresser aux problèmes d'organisation de l'espace. La fondation de la science régionale, la prise en compte des mécanismes macroéconomiques, la curiosité nouvelle pour les économies d'échelle et externes rapprochent l'économie, la géographie économique (deuxième manière) et l'aménagement. 3- Depuis 1970, la faillite des recettes proposées dans les années 1950 ou 1960 conduit à un changement profond de perspective : l'accent est mis sur le développement par le bas, sur le rôle des localisations en grappe et sur l'économie de la connaissance.

\section{INDEX}

Mots-clés: espace, territoire, géographie économique, théorie spatiale, relations internationales Keywords: space, territory, economic geography, spatial theory, international relations theory Palavras-chave: espaço, território, geografia económica, teoria espacial, relações internacionais 
AUTHOR

PAUL CLAVAL

Universidade de Paris-Sorbonne 